\title{
LA REPRESENTACIÓN DEL PODER EN LAS COMUNIDADES PROTOHISTÓRICAS DEL NOROESTE PENINSULAR. EXCELENCIA MASCULINA Y COTIDIANIDAD FEMENINA ${ }^{1}$
}

\author{
Mónica González Santana²
}

Resumen: dentro de las estrategias de acceso al poder de las élites masculinas, la articulación y dominio de los espacios de representación servirían de garantía tanto a la legitimación como a la consolidación de las desigualdades sociales. Una garantía que se apoyaba en el control de las armas, los rituales y la autoridad. En ese sentido, el estudio, como parte del lenguaje simbólico del poder, de los espacios y materiales rescatados nos ayuda a entender cómo se construyeron las diferencias de género y con ellas las desigualdades entre hombres y mujeres.

Palabras clave: protohistoria, arqueología, espacios, género, poder, patriarcado, excelencia y cotidianidad.

Title in English: The Representation of Power in the Northwest Peninsular Protohistoric Communities. Masculine Excellence and Feminine Cotidianity

Abstract: In the power strategies of masculine elites, the articulation and domination of representational spaces would serve to guarantee their legitimacy, but they would also consolidate social inequalities. Masculine power, shored up by development of defensive weaponry, was organised through control of weapons, rules and rituals. This study of spaces and materials will assist in understanding how such societies, through this symbolic language of power, constructed gender differences and thereby created inequalities between men and women.

Key words: protohistory, archaeology, spaces, gender, power, patriarchy, excellence and cotidianity.

Las investigaciones llevadas a cabo en los últimos años en Galicia han supuesto un claro avance en cuanto a la identificación y análisis de los patrones de asentamiento

\footnotetext{
${ }^{1}$ Fecha de recepción: 28/08/2013

Fecha de aceptación: 17/11/2013

${ }^{2}$ Doctora en Historia, integrante del Grupo de Investigación Deméter, Universidad de Oviedo, España;

mokasantana@gmail.com.
} 
de las comunidades del Bronce ${ }^{3}$. En ese sentido, se han observado una serie de pautas comunes que indican cierto carácter regulador en las dinámicas de ocupación espacial. De esta forma, la demarcación, uso y abandono cíclico de las distintas partes del territorio, sugieren la conformación de modelos más o menos estables definidos a través de los usos funerarios y cultuales (Ayán y Parcero 2007: 7). De ahí la imperceptibilidad de los espacios domésticos y su carácter estacional. Así pues, y en principio, se podría apuntar cómo en la construcción del territorio, dos espacios, el funerario y el cultual, servirían a la visibilización y monumentalización del discurso que justificaría y legitimaría su uso y control. Estamos ante una exhibición pública del poder territorial estructurada fuera del ámbito habitacional. Ahora bien, partiendo de estas consideraciones, qué explicaciones podemos dar a los procesos de monumentalización y consolidación doméstica que comienzan a acentuarse a finales del Bronce, y por tanto, qué respuestas podemos ofrecer a formulación de nuevas estrategias de exhibición pública del poder territorial a nivel funerario, cultual y habitacional.

La reutilización, durante el Bronce, de túmulos como los de Aizibita y Carracadia, ambos en Navarra, Ausokoi I en Guipúzcoa o Cabritos 1 en Amarante (Oporto), vendría a confirmar la larga pervivencia que tuvieron este tipo de soluciones constructivas. De igual modo, la fundación ex novo de monumentos como los de Piedrafita (Túmulo V) o Monte Deva V (Gijón, Asturias), refutarían su trascendencia temporal y lo que parece una preferencia, a diferencia de periodos anteriores, por las soluciones "paramegalíticas" y las sepulturas individualizadas (de Blas 2006). A este panorama, se sumarían los enterramientos en cuevas como prácticas "heredadas" a las que se añadirían los levantamientos de cairns, cistas y fosas (Fábregas y Bradley 1995a). En ese sentido, yacimientos como los de Agro de Nogueira o Mandón, en Galicia, señalan como durante el Bronce Inicial se observa la existencia y convivencia tanto de distintos ambientes, como de tratamientos funerarios "incluyendo cremación e inhumación, cistas o fosas, acompañadas de escaso o nulo ajuar" (Fábregas y Bradley 1995a: 155). Teniendo en cuenta esta gran variabilidad, lo que interesa destacar es, por un lado, la

\footnotetext{
${ }^{3}$ Avances, en su mayoría, favorecidos por los trabajos de seguimiento, control e impacto arqueológico de autovías, redes de gasificación y parques eólicos evaluados por el Laboratorio de Arqueoloxía e Formas Culturais da Univerdidades de Santiago de Compostela y publicados en la serie TAPA.
} 
voluntad de generar cierta continuidad mediante la vinculación o generación de espacios monumentales, y por otro lado, la invisibilización que, a priori, se busca en los usos no monumentalizados ${ }^{4}$. Estamos, por tanto, ante una práctica social, el tratamiento de la muerte, que ha generado dos productos sociales diferenciados en función, entre otras cosas, de la monumentalización, la vinculación al pasado, la inversión colectiva y el beneficio individualizado, con un efecto social como es la creación de un uso noigualitario y por tanto privilegiado del espacio (Criado 1993). Por todo ello, se plantea la existencia de un sector o grupo social que utilizaría determinadas prácticas funerarias como estrategia de diferenciación. Prácticas que, decíamos, servían a la definición y demarcación del espacio humanizado, formando parte del discurso de un poder, el territorial, basado, entre otras cosas, en la legitimidad que otorgaban los antepasados. Si esto es así, podemos aventurar que ese grupo social consiguió apropiarse de la vinculación al pasado mediante la reutilización y reinterpretación de los espacios funerarios monumentalizados. De esta forma, la fórmula legitimadora territorioantepasados-colectividad pasaba a un segundo plano desplazada por la creación de un modelo sectorial en el que la instauración de genealogías míticas facilitaba y/o justificaba el acceso a la autoridad: antepasados-grupo privilegiado (Polignac 1989). Se reelaboraba así el pasado como "reserva de imágenes, de símbolos, de modelos de acción que permiten emplear una historia idealizada, construida y reconstruida según las necesidades y al servicio del poder" (Balandier 1994: 19). Cabe ahora preguntarse, qué otras medidas complementaron este acceso al poder y por tanto, averiguar qué estrategias se destinaron a solventar las resistencias que la instauración de desigualdades hubo de generar.

Las exigencias que la creación, mantenimiento y explotación de un territorio plantea a cualquier grupo humano pasan, entre otras medidas, por la justificación (acumulación de capital simbólico) y consolidación (defensa y control) ${ }^{5}$. El perfeccionamiento que implica una mejora en la explotación y mantenimiento territorial

\footnotetext{
${ }^{4}$ Con respecto a la reutilización del pasado, Pierre Bourdieu plantea cómo las formas sociales son reproducidas, apropiadas, desplazadas y transformadas desde el presente, en las prácticas y las interacciones de la cotidianidad social (1977).

${ }^{5}$ Utilizo la terminología propuesta por Pierre Bourdieu (1986) "capital simbólico" como aquel capital que legitima al resto: social, económico y cultural.
} 
hubo de generar una mayor especialización en la defensa y control. Por ello, no parece desacertado pensar que la usurpación del pasado colectivo corrió de la mano de la creación de un sector social especializado, cuyo discurso de vinculación directa con el territorio (antepasados) no solo justificaba su cohesión como grupo sino el establecimiento, como decíamos, de determinados privilegios en función de la puesta en escena de esa vinculación. Y es en esa teatralización donde cobran sentido los espacios funerarios, pero también, y dado que el territorio necesitaba, para consolidarse, tanto de la defensa mágico-religiosa (control ritual) como de la protección armada (control bélico), los llamados espacios cultuales que, como apuntaba al principio, ayudarían a la definición de los modelos territoriales. Estamos, por tanto, ante la manifestación espacial del entramado discursivo que daría legitimidad a la formación de grupos sociales empoderados en función de su especialización. Por ello se hace necesario avanzar, para profundizar en este desarrollo, sobre dos cuestiones que considero fundamentales: la simbología y la ubicación de estos "centros" cultuales.

Son numerosos los grabados en los que aparecen armas (puñales, alabardas, etc.), agrupaciones que, en el caso gallego, parecen asociarse "con los límites superiores de las áreas de asentamiento" (Bradley y Fábregas 1999: 105), situándose, de esta forma, en posiciones que ejercen gran control visual sobre el entorno. Resulta curiosa, además, la asociación que se establece, en determinados emplazamientos, entre este tipo de representaciones y la aparición de depósitos de armas ritualizados. Como señalan Ramón Fábregas y Richard Bradley:

podríamos incluso observar algunas semejanzas entre depósitos y petroglifos respecto a la ergología metálica presente: así en el Ayuntamiento de Rianxo (La Coruña) aparecen muy próximos entre sí una piedra con grabados (Foxa da Vella) y el depósito de Monte Lioira, encontrándose en ambos yacimientos alabardas y puñales. Aún más revelador, en ciertas estaciones como la de O Rarnallal (Campolameiro, Pontevedra), las armas representadas (aquí solo puñales) parecen estar dispuestos en posición de almacenaje. (1995a: 155)

Al hilo de lo expuesto, merecen especial mención los casos asturianos del conocido como "Ídolo de Peña Tú" (Sierra Plana de la Borbolla, Llanes) y de las figuras del "Abrigo del Ganado" (Fresnéu, Teverga), ambos ejemplos contienen 
representaciones de guerreros (de Blas 2003). En general, y sin meternos en estilos o la existencia de otras representaciones (zoomórficas, geométricas, etc.) lo que me interesa destacar es, por un lado, la conexión que se establece entre la demarcación-control territorial, ciertos monumentos naturales, las rocas insculturadas y las armas, y por otro, la posibilidad de observar, en palabras de Jose Manuel Vázquez Varela, "la existencia de especialistas religiosos que en el transcurso de un rito graban" (1999: 79) determinados símbolos, dotando de poder mágico-religioso el espacio utilizado para el ritual. Teniendo esto en cuenta, Blanca Fernández- Albalat (1990) y el propio Jose Manuel Vázquez Varela (1999), plantean la existencia de ciertas similitudes entre las cofradías de guerreros descritas para el mundo indoeuropeo y los grupos de especialistas en la defensa del territorio que hemos venido manejando:

Grupos autónomos o integrados en la tribu que a menudo tienen un carácter marginal y practican la caza y la guerra. Esta suele ser de pillaje y ostentación para adquirir estatus. Están vinculados con una divinidad guerrera a la que ofrecen sacrificios, a veces en lugares sagrados específicos como grandes rocas en zonas marginales, en la tierra de nadie, en los límites de las comunidades dónde se celebran asambleas, fiestas religiosas, ritos iniciáticos y, a veces, reuniones sociales, administrativas, jurídicas y económicas. (Varela 1999: 77)

En su momento Edmund Leach (1993) elaboró un esquema con lo que consideraba las características básicas de un rito de paso atribuibles a un gran número de sociedades y que irían desde el abandono, por parte del iniciado, de su existencia anterior, pasando por la separación y segregación de lo cotidiano hasta su reintegración en la vida social. En ese sentido Diodoro de Sicilia destaca que:

Una práctica peculiar tiene lugar entre los iberos y especialmente entre los lusitanos. Cuando sus jóvenes alcanzan la plenitud de su fuerza física, aquellos que son los más pobres entre ellos en bienes materiales pero son excelentes por su vigor y audacia, se equipan sólo con su valor y sus brazos y se retiran a las montañas. Allí forman bandas de considerable tamaño con las que bajan hasta Iberia reuniendo riquezas mediante el pillaje. (Biblioteca Histórica, V, 34, 6)

Soy consciente de las críticas que la inclusión de este texto puede suscitar, tanto en su contextualización como en la intencionalidad puesta en lo escrito. Pese a esa carga ideológica y la homogeneidad que supone la creación de un relato de "autoafirmación 
cultural" donde la incorporación del mito y la "retórica de la alteridad", como medios de comparación entre lo civilizado y lo bárbaro, son una constante en la definición de "el otro", considero que los autores grecolatinos, más que mentir, utilizaron la exageración y/o selección de ciertos datos en detrimento de otros con la clara intención de ofrecer un relato ajustado a sus propósitos (González Santana 2010). Un ejemplo de esa manipulación serían las noticias vertidas por Estrabón en su Geografía, y en concreto, el discurso que establece desde el modelo ideal greco-latino de hombre y mujer: hombre/civilizado/público-mujer/naturaleza/privado. De esta forma, en la descripción de los "montañeses" destacaría aquellos rasgos que a ojos del "civilizado" supondrían una clara inversión de roles. Que las mujeres trabajaran el campo era y es algo habitual a lo largo del mundo, pero no es el ideal y menos cuando señalas que los hombres únicamente se dedican a la guerra, lo que resaltaría la incapacidad de éstos para compatibilizar ambas labores. En definitiva, no se trata tanto de mentir como de inferir a la par que obviar ciertos datos. Siguiendo con el tema de las cofradías guerreras se puede observar:

Tabla I. Espacios cultuales

\begin{tabular}{|l|r|}
\hline \multicolumn{1}{|c|}{$\begin{array}{c}\text { Espacios cultuales cofradías guerreas (Vázquez } \\
\text { Varela, 1999) }\end{array}$} & Espacios cultuales Noroeste peninsular \\
\hline Grandes rocas & Grandes rocas al estilo Peña Tú o Chao Samartín. \\
\hline Zonas marginales, tierra de nadie. & Áreas marginales no productivas \\
\hline Límites de las comunidades & zonas de paso \\
\hline Celebración de asambleas, rituales, etc. & Celebraciones rituales, etc. \\
\hline
\end{tabular}

Resulta arriesgado, claro está, establecer analogías entre una descripción, la de las cofradías guerreras pertenecientes al Hierro Europeo Occidental, y la de las estaciones rupestres o petroglifos con armas grabadas, en su mayoría, pertenecientes al Bronce. Ahora bien, si como apuntábamos, en los procesos de monumentalización habitacional, los grupos especialistas en el control y la defensa territorial habían reutilizado y reinterpretado los espacios funerarios monumentalizados, no parece tan desatinado pensar que hubieran hecho uso, en esa misma línea y como señala Manuel Santos Estévez (2008), de espacios con una larga tradición de ocupación cultual. De esta forma, 
la temporalidad del contenido simbólico no se limitaría al momento de su ejecución contando, pues, con una larga biografía (García Quintela y Seoane-Veiga 2011: 244). En ese sentido, la famosa roca situada en la llamada "acrópolis" del Chao Samartin (Grandas de Salime, Asturias), podría responder a este tipo de consideraciones pese a que no presenta manifestaciones artísticas. De su relación con el mundo cultual dan cuenta las excavaciones realizadas en esta zona, cuya ocupación se fecha entre el 801 y el 778 a. C. Se describió la existencia de un área delimitada por un cierre perimetral, en cuyo acceso apareció una cista en la que se depositó una calota craneal posiblemente femenina. Se documentaron también los restos de una hoguera en la base de la roca y de una gran cabaña que albergaba un ajuar realmente singular relacionado con los banquetes rituales (Villa 2003). Ejemplos similares al del Chao los encontramos en asentamientos gallegos como Pequeno de Neixón, Torroso, Coto da Pena, A Lanzada, Campa Torres y posiblemente Llagú, éstos dos últimos en Asturias. En ese mismo orden de cosas, resulta revelador observar el número de castros en los que aparecen rocas insculturadas formando parte de las construcciones, bien ocultas bajo la cimentación, bien reutilizadas como paramentos. De igual modo, se documentan numerosos petroglifos que conservan su posición original y que forman parte destacada del paisaje tanto en el interior como en el exterior de los recintos. De esta serie de ejemplos podemos inferir el sobrado interés que los habitantes de estos parajes pusieron en la incorporación de tales representaciones al día a día de las comunidades (Alfayé 2009) ${ }^{6}$.

Con lo expuesto, se puede apuntar hacia la conexión que se establece entre ciertos espacios que, pudiendo haber partido de tradiciones anteriores, fueron adoptados y reinterpretados bajo las nuevas necesidades sociales, lo que me llevaría relacionar esa

\footnotetext{
${ }^{6}$ Dentro de esa incorporación o integración se pueden observar tres actitudes o maneras de considerar al objeto (las grandes rocas y los motivos insculturados). Como protector y benefactor a nivel familiar. El famoso Castro de Santa Tegra (A Guarda, Pontevedra) aportó numerosa información al respecto, documentándose varios grabados formando parte de la cimentación de algunas unidades domésticas (Alfayé 2009). Como protector y benefactor a nivel comunitario, formando parte del entramado de las murallas. Un buen ejemplo lo tenemos en Castro Rupario (Rois, Brión, A Coruña). Como hito relacionado con la perceptibilidad y monumentalización del espacio cultual que, probablemente, podamos emparentar con el citado caso del Chao Samartin. En el conocido como "Castrino de Conxo" (Santiago de Compostela, A Coruña), se localiza una roca en la parte más elevada del castro, en la que aparecen insculturadas un grupo de alabardas, puñales y/o espadas cortas, así como un conjunto de figuras interpretadas como posibles máscaras o escudos, entre otros (Peña y Vázquez Varela 1979).
} 
"adopción" con los procesos de normalización del poder del grupo directamente relacionado con la protección y defensa del territorio. La diferencia, entiendo, con respecto al pasado está en la integración o separación de los espacios rituales del ámbito poblacional y en el papel que los defensores jugaron en este proceso. De esta forma, observamos cómo se pasa de una clara segregación de ambientes -espacios rituales relacionados con la defensa, por un lado, y recintos habitacionales nomonumentalizados, por otro- a su integración en la estructura del poblado o, en su defecto, a que el poblado crezca al amparo de su presencia, eso sí, claramente diferenciado. El discurso simbólico, ahora, trata de establecer una normalización que provoque la incorporación a la vida "cívica" -no en el sentido clásico, sino en el de comunidad- de los escenarios del poder. Agregar estos espacios al mundo cotidiano produciría una clara exhibición del poder, pero también la percepción de una mayor "cercanía”. A lo excepcionalidad y la segregación se unía, ahora, una nueva preocupación basada en la obligatoriedad de crear un producto codificado a través de lo ordinario que diera cobertura a las relaciones sociales gestadas al calor de la consolidación de estos grupos de especialistas. Unas relaciones en las que el mantenimiento de privilegios, vía grupo-linaje, hubo de jugar un papel fundamental, de ahí la necesidad de trasladar ciertos escenarios del poder a los ambientes fronterizos del día a día de las familias privilegiadas. De esta forma, la simbología del poder territorial se incorporaba, vía apropiación, al entramado familiar añadiendo, así mismo, un elemento nuevo que facilitaría esa vinculación: la monumentalización de los recintos habitacionales a través de los sistemas defensivos. En ese sentido, conseguían, además, ocultar las políticas de consolidación familiar dado que el esfuerzo monumentalizador recaía en la defensa del recinto cultual, símbolo del Territorio, y no en las propias unidades domésticas que, a ojos de la colectividad, "disfrutaban" de ese espacio en calidad de garantes de la geografía comunitaria. En mi opinión, el carácter igualitario de la arquitectura doméstica respondería, precisamente, a la necesidad de disimular la consolidación de los sistemas de acceso al poder y, por tanto, a la obligatoriedad de crear un modelo de "ficción comunal" (Martínez y Afonso 2003: 84) que diera salida a las tensiones y resistencias sociales generadas. 
En definitiva, hemos estado hablando de un grupo que se había hecho con el dominio y la autoridad obteniendo una serie de privilegios en función, entre otras cosas, de su especialización y la capacidad de legitimarse mediante el control del tiempo (pasado mítico) y el espacio (Territorio). Un control proyectado en la monumentalización y visibilización de los espacios de representación, lo que me llevaba a plantear que en la propia monumentalización de algunos recintos habitacionales podemos ver su asimilación con el poder $^{7}$. Es decir, su actuación como centros de autoridad y dominio territorial ${ }^{8}$. Ahora bien, en ese escenario social vertebrado desde las tensiones que implica toda relación de poder, en contadas ocasiones se incluye el género como categoría de análisis $\mathrm{y}$, por tanto, pocas veces se profundiza en la correspondencia que hombres y mujeres establecieron con el ordenamiento y gestión del espacio y el tiempo (Hernando 2000). En ese sentido, cabría cuestionarnos si en los ámbitos de representación, hombres y mujeres compartirían un mismo grado de reconocimiento, prestigio y excelencia (Amorós 1994).

Apuntaba, anteriormente, la singularidad de los objetos recuperados en la gran cabaña del Chao Samartín (Asturias). El juego de piezas se corresponde con fragmentos de cerámica hecha a mano, de factura tosca y pastas porosas de gran ligereza, con una gran muestra de materiales de bronce: fragmentos de un gran disco de 1, 15m de diámetro, con alma de madera, planchas y tiras circulares de metal, restos de calderos de remaches y sítulas, objetos, éstos últimos ampliamente reconocidos y relacionados con

\footnotetext{
${ }^{7}$ Un ejemplo de lo que quiero decir lo encontramos en el caso descrito por Xúlio Carballo para la Comarca de Trasdeza en Pontevedra. En dicha zona, la posición estratégica de cada uno de los espacios habitacionales dibujaría un mapa de "visibilidad solidaria" destinado a ejercer un mayor control sobre el territorio, lo que posibilitaría "comunicacions ópticas entre os castros da comarca, e destas coas veciñas, a través de sinais nocturnos de lume ou diurnos de fume...estas transmisións, realizadas de forma temporal, estan testemuñadas no mundo antigo polas fontes clásicas" (Carballo 1986: 66). Los modelos propuestos por Pastor Fábrega para la comarca de Ortegal (Coruña) apuntan también a la singularidad de ciertos castros; en este caso el de Ladrido (Ría de Ortigueria), del que el autor habla como un poblado con una funcionalidad "no tanto orientada a su propia defensa (accesibilidad media-baja; Modelo dos) como a la integración y control del grupo (visibilidad) así como la formalización de un referente del mismo (altitud relativa y visibilización) (2005: 145). Ver también los trabajos de César Parcero Oubiña sobre poblamiento y espacio social (en bibliografía).

${ }^{8}$ En ese sentido planteamientos como los de Alfonso Fanjul señalan que "parece materialmente imposible que en la Asturias de la Edad del Hierro se viviese solo en castros" (2004: 47). El mismo autor basa sus consideraciones en la probada existencia "de fuertes tradiciones materiales y económicas anteriores, provenientes de la Edad del Bronce, donde el poblamiento era mucho más extenso, incluyendo áreas que hoy carecen de castros" (2004: 48). En ese mismo sentido, Xavier Peñalver (2001) analiza las estrategias y variabilidad de poblamiento en Euskadi.
} 
el consumo cárnico ritual (Bradley 2005). En general, los contextos en los que aparecen este tipo de ajuares:

Nos sugieren la existencia de ceremonias de clara connotación ritual, que tendrían lugar en cuevas y quizás asociadas a momentos iniciáticos. En paralelo, las grandes cabañas podrían actuar como lugar de reunión y banquete de grupos amplios, con motivos muy distintos que irían desde la exhibición de riqueza y el reforzamiento de los lazos de clientela hasta las ceremonias de guerra o los actos de hospitalidad. (Aranda y Esquivel 2008)

En las sociedades del momento existía, sin duda, una vinculación relevante entre la ideología de la guerra y los banquetes, que podrían relacionarse también con la movilización de fuerza de trabajo (Armada 2008: 153) ${ }^{9}$. De ahí podemos extraer que el rol jugado por esta clase de objetos excedía lo cotidiano, atesorando, por tanto, un gran valor social que se hacía ya patente en el momento de su elaboración, ya que ésta:

Requería una inversión de tiempo y esfuerzo muy superior a la que observamos en otros objetos del período, como hachas, lanzas o espada. Estas piezas serían creaciones de artesanos con habilidades superiores a las del broncista común, actuando la complejidad tecnológica como una componente fundamental del rol social del objeto. (Armada 2008: 139)

Se puede señalar, por tanto, que existe una clara vinculación entre la creación de determinados espacios, los restos materiales allí encontrados y el mundo ritual de los banquetes y la guerra. En esa misma línea, los famosos bronces sacrificiales del Instituto de Valencia de Don Juan, del Museo Arqueológico Nacional o el depositado en el Museo de Pontevedra, entre otros, nos trasladan, mediante su iconografía, a un mundo ritualizado en el que se funden los elementos anteriormente expuestos ${ }^{10}$. De

\footnotetext{
${ }^{9}$ Cabe hacer espacial énfasis en el hecho de que la mayoría de los hallazgos de calderos peninsulares, aparecen en contextos poblacionales, siendo su estado fragmentario lo que podía responder a un troceado intencional bien como chatarra, bien para su reciclado. De todas formas, parece clara su vinculación con espacios rituales, así un fragmento de caldero con remaches, proveniente del poblado de Satinha (Amares, Braga, Portugal), se localizó en una cabaña siendo interpretada ésta última como un espacio de carácter ritual. De la misma manera los fragmentos hallados en Hío (Cangas do Morrazo, Pontevedra) correspondiente a un depósito ritual, o el famoso caldero de Cabárceno sugieren esa vinculación entre objeto y ritualización. Sobre el carácter ritual de éstos y otros objetos como los asadores o los ganchos de carne vid., entre otros, los trabajos de Richard Bradley (2005), Xose-Lois Armada (2008) o Alfredo González Rubial (2007).

${ }^{10}$ Sobre los bronces rituales vid. Xose Lois Armada y Óscar García (2003).
} 
igual modo, la conocida como "Diadema de Moñes" (Piloña, Asturias), al margen de los debates cronológicos que pueda plantear, recoge un escenario único para el conocimiento de estas comunidades. Por ello se hace necesario una relectura de la misma, a través del género, para observar en qué medida podemos hablar de una masculinización del poder.

De modo muy general, se puede observar en los fragmentos conservados, una ambientación acuática con representación de distintos animales (fig. 2) y una serie de personajes cuyas características, indumentaria y objetos que los acompañan sugieren la representación de lo que parece un grupo de hombres claramente diferenciados en función de su pertenencia a la caballería, infantería o sacerdocio -dirigen y controlan cultos, rituales y sacrificios- (fig. 3). Estamos, pues, ante una escenografía en la que se aúna el mundo de la guerra -formación y destino del guerrero- con la representación de su apoteosis a través del ritual de la muerte. En ese sentido, tanto Marco Simón (1994) como M. Virgilio García Quintela (1999), señalan ese tránsito al Más Allá que se asemejaría al recogido en el famoso "Caldero de Gundestrup" (Dinamarca). Ahora bien, estando totalmente de acuerdo con esta interpretación, me gustaría añadir, además, la posibilidad de observar en esta proyección, el rito de paso masculino a la vida adulta, cuando el infante pasa a caballero. De esta forma, la muerte del niño supone el verdadero nacimiento como hombre, ya no a través del canal de parto materno, sino mediante la ingesta (o el baño según la representación contenida en Gundestrup) del caldo contenido en los calderos, y por tanto vía masculina. En ese "renacer" paternogenético, la muerte no supone el fin, sino el tránsito de lo físico a lo espiritual. De ahí que en el fragmento conservado en Saint Germain-en-Laye (Francia), aparezcan, en esa ambientación de tránsito acuático, una serie de personajes y de posibles cabezas impresas en el extremo distal, lo que podría sugerir una conexión con la concepción céltica de la cabeza como depositaria del espíritu y la entrada en el Más Allá (Markale 1992): 
Tabla II. Diagrama con la interpretación acerca de la ambientación faunística contenida en la "Diadema de Moñes"

\begin{tabular}{|l|c|r|}
\hline Équidos & & Cánidos \\
Psicopompo. & & Caza, curación, mundo ctónico. \\
\hline Aves acuáticas & Fondo acuático & Teleósteos (probablemente salmón). \\
$\begin{array}{l}\text { Simbolismo solar, ascensión, tránsito y } \\
\text { unión. }\end{array}$ & Mundo cíclico, & Ascensión y conocimiento \\
& espacio de tránsito. & \\
\end{tabular}

Fuentes: Mónica González Santana, 2012.

Tabla III. Personajes de la "Diadema de Moñes".

\begin{tabular}{|c|c|c|c|c|c|}
\hline \multicolumn{6}{|c|}{ PERSONAJES } \\
\hline \multicolumn{2}{|c|}{ CABALLERÍA } & \multicolumn{2}{|c|}{ INFANTERÍA } & \multicolumn{2}{|c|}{ SACERDOTES } \\
\hline $\begin{array}{l}\text { Indumentaria y } \\
\text { equipamiento }\end{array}$ & Morfología & $\begin{array}{c}\text { Indumentaria } \\
\text { y } \\
\text { equipamiento }\end{array}$ & Morfología & $\begin{array}{c}\text { Indumentaria } \\
\text { y } \\
\text { equipamiento }\end{array}$ & Morfología \\
\hline Caetra & Rostro ornitomorfo & Caetra & $\begin{array}{c}\text { Rostro } \\
\text { ornitomorfo }\end{array}$ & Cinturón & $\begin{array}{r}\text { Rostro } \\
\text { ornitomorfo } \\
\end{array}$ \\
\hline Venablo & $\begin{array}{c}\text { Composición a la } \\
\text { derecha }\end{array}$ & Lanzas & $\begin{array}{c}\text { Composición } \\
\text { a la derecha }\end{array}$ & ¿Desnudez? & $\begin{array}{r}\text { Cabello } \\
\text { recogido en } \\
\text { cola } \\
\end{array}$ \\
\hline Penacho curvo & & $\begin{array}{c}\text { Espada corta o } \\
\text { puñal }\end{array}$ & & & $\begin{array}{r}\text { Composición } \\
\text { hacia la } \\
\text { izquierda. }\end{array}$ \\
\hline $\begin{array}{l}\text { Casco de triple } \\
\text { cornamenta }\end{array}$ & & Cinturón & & & \\
\hline Torques & & $\begin{array}{c}\text { Casco de triple } \\
\text { cornamenta }\end{array}$ & & & \\
\hline ¿Desnudez? & & ¿Desnudez? & & & \\
\hline
\end{tabular}

Fuentes: Mónica González Santana, 2012.

La concepción del Más Allá, la inmortalidad, el poder o la guerra que observamos, tanto en la iconografía de la diadema como en la decoración presente un una amplia mayoría de estelas consideradas como vadinienses u orgenomescas (pueblos prerromanos de la zona oriental del actual territorio asturiano): caballos, ciervos, torques o medias lunas, árboles, tetrapétalas, etc.; nos permiten alcanzar un mayor acercamiento al desarrollo ideológico e identitario de estas comunidades. De nuevo soy consciente del inconveniente que supone hablar de identidades, mentalidades, ideologías, etc. cuando nos enfrentamos a sociedades ágrafas, no obstante insisto en la necesidad de acercarnos al objeto para aventurarnos en posibles interpretaciones ya que 
como señala $\mathrm{M}^{\mathrm{a}}$ José Bóveda “o seu valor histórico trascende a propia peza converténdoa nun vehículo de comunicación directa co mundo antiguo" (1999: 12). En ese sentido, hemos de averiguar en qué medida podemos trasladar el discurso presente en nuestra diadema, a la realidad social de unas comunidades que, repetidamente, han sido y son consideradas como de base igualitaria ${ }^{11}$.

Atendiendo a la descripción de Marco Simón la existencia de grupos guerreros se observa como un hecho, siendo las diademas "la expresión del prestigio de una élite principesca, del tipo de la reflejada en la estela de Pedreira (Vegadeo)" (Simón 1994: 327). Ahora bien, cabe la posibilidad de plantearnos si éste es un fenómeno aislado que, de ninguna manera, se constituye en espejo de la realidad social con la que se relacionó o si, por el contrario, y pese su excepcionalidad, podemos hallar paralelos en otro tipo de representaciones y soportes. En ese sentido, la aparición de otras "diademas" a lo largo del Noroeste, así como torques, cascos, brazaletes, pendientes, etc. ponen de manifiesto la importancia, difusión y desarrollo de un artesanado especializado en la realización de un tipo de bienes suntuarios directamente relacionados con la acumulación de capital simbólico. Una acumulación que, si tenemos en cuenta las argumentaciones de Francisco J. Sánchez Palencia (1983) hubo de recaer en la capacidad de un sector, grupo o familia para hacerse con el control de estos bienes. Dejando a un lado la importancia de este tipo de bienes suntuarios, y volviendo a la iconografía presente en la diadema, probablemente podamos decir que no es un caso aislado. En ese sentido, estatuas de guerreros han aparecido en Capeludos, Quintela, Lezenho, Sao Juliao, Sanfins o Meixedo, todos ellos en el Conventus Bracarensis. No voy a entrar en la polémica suscitada por la cronología de tales manifestaciones,

\footnotetext{
${ }^{11}$ Esta teoría vendría a basarse tanto en el registro arqueológico como en la compilación de los materiales epigráficos y la lectura de las fuentes clásicas. Estas dos últimas fuentes de información incorporarían a su vez el elemento femenino al mundo castreño, incidiendo en la importancia del mismo en función de un pasado matriarcal que el tiempo iría desarticulando, pero que sería rastreable a través de los usos matrilinealistas de estas comunidades. De la interpretación de las poblaciones castreñas como comunidades campesinas de base igualitaria, destacan, entre otros, los trabajos de $\mathrm{M}^{\mathrm{a}}$ Dolores Fernández Posse (1997, 1998) e Inés Sastre Prats (2001). Especial mención merecen al respecto las consideraciones de Alfredo González Rubial, cuando se cuestiona si realmente existen sociedades igualitarias, asumiendo que "probablemente no. Incluso en las sociedades isonómicas se constatan diferencias entre sus miembros, fundamentalmente por razones de género. Cuando hablamos de sociedades igualitarias debemos ser conscientes (...) de que estamos omitiendo una forma de desigualdad que afecta a la mitad de la población humana" (2003: 90).
} 
simplemente traigo a colación su existencia en función de la simbología que las acompaña: el poder y los guerreros. En esa misma línea, la cerámica de Cogotas, o la de Numancia, por poner algunos ejemplos, nos muestran también un mundo con claras similitudes iconográficas con la diadema de Moñes (tocados de triple cornamenta, figuras ornitomorfas, caballos etc.), en el que quedan asociados lo masculino y la guerra. Por otro lado, e independientemente del soporte utilizado, se puede apuntar hacia un propósito final, común a la ejecución de este tipo de manifestaciones artísticas, la transmisión y difusión de un sistema de valores en el que prima la guerra y las actividades bélicas como fórmulas de acceso al poder. En ese sentido, la cerámica griega constituye un magnífico ejemplo de la transmisión y difusión de ideas, con una temática más que recurrente y un mensaje fácilmente reconocible: la división social entre hombres-guerreros y mujeres-madres ${ }^{12}$.

De igual modo la epigrafía del Noroeste revela la existencia de una serie de personajes-hombres con el cargo de princeps que nos muestran la presencia, al menos en época romana, de una serie de individuos con un poder real sobre la población. Véase el caso de Vecius (CIL II 2585), de Doviderus (HEp 7, 1997, 380) de Nicer (AE 1946, 121) o el nombrado como precepto, Cornelius Maternus (HEp. 2, 1990: 449). Hemos de tener en cuenta que, como señala Inés Sastre, en "la epigrafía latina las inscripciones no estaban pensadas para ser leídas o, tal vez mejor dicho, no estaban pensadas solo para ser leídas" (Sastre 2004: 15). En necesario partir de la base de que, entre los objetivos de los textos epigráficos, el que fueran efectivamente leídos y entendidos era una cuestión secundaria. La comprensión del texto propiamente dicho daba lugar a un nivel de comunicación que no era el único ni el más importante, convirtiéndose en fundamentales también otras cuestiones como su inserción en la monumentalización de los espacios públicos y en los programas iconográficos destinados a cargar de contenido simbólico la propia existencia de la pieza. De este modo, lo escrito formaba parte de la representación política de los grupos dominantes.

\footnotetext{
12 El hecho de que estemos ante sociedades ágrafas fomenta el uso de otros recursos como medios capaces de difundir determinada ideología. En este caso, la que establece unos privilegios en función del hecho de ser varón y guerrero. Sobre la división de funciones en función del sexo y el rol social de madres al que las mujeres griegas se veían abocadas, vid. los trabajos de Ana Iriarte (2002) o Nicole Loraux (2004) entre otros.
} 
Cabe recordar, también, la eficaz organización de la que dieron notable muestra los habitantes de estos lugares, a la hora de enfrentarse con el invasor, en este caso el Imperio Romano. Teniendo en cuenta estas circunstancias, todo parece apuntar hacia la posibilidad de que la epigrafía nos esté remitiendo a la existencia prerromana de una serie de personajes o grupos con un poder fáctico sobre la población. Situación que Roma sabría aprovechar, a la hora de poner en marcha sus propios intereses estratégicos y administrativos (pactos, traiciones, comercio o explotación minera), antes y después de la conquista armada (Rodríguez Neila, 1998).

Con lo expuesto, parece más que evidente que la asociación que se da entre ciertos espacios -su factura, funcionalidad y carácter simbólico- y los objetos hallados en los mismos, nos traslada a una escenificación de ciertas actividades masculinas que vemos retratadas en textos como los de Estrabón; es decir, la celebración de banquetes o reuniones que consagrarían determinados actos sociales ${ }^{13}$. Podemos hablar, a modo de hipótesis, de verdaderas élites masculinas formadas al calor de la acción bélica, la defensa territorial y el control del ritual. Esas élites que, como decía, parecen venir gestándose desde el bronce y que buscarían la reafirmación de su posición social mediante la vinculación a un pasado mitificado ${ }^{14}$. Estaríamos señalando la existencia de posibles jefaturas con un dominio real sobre la población. Un poder que buscará su legitimación, entre otros, en el discurso espacial, reproduciendo determinados ámbitos de escenificación pública en los que el grupo de los privilegiados se vería ampliamente representado y visibilizado. De esta forma, en la convergencia entre lo material y lo simbólico se puede observar como en los usos tradicionales se procede a la interpretación y reinterpretación de la realidad en favor de unos determinados intereses. De ahí la incorporación, como venimos señalando, al entramado habitacional de elementos materiales y/o naturales con una dilatada biografía social directamente relacionada con el control del territorio y la conformación de un grupo social que se

\footnotetext{
${ }^{13}$ “'Este recinto no muestra indicio alguno de uso residencial. Si en principio, su localización en altura justificó el uso del término acrópolis en una acepción estrictamente topográfica, con el avance de las excavaciones y la documentación de una ambiente ajeno a todo uso doméstico, esta denominación se ha ido aproximando a la acepción clásica de temenos o espacio de carácter sacro" (Villa 2003: 31).

14 En palabras de Almudena Hernando "la legitimación tiene que ser ideológica, habiendo tomado en la mayor parte de los procesos históricos la forma de sistemas religiosos organizados y/o 'ideologías heroicas"” (2002: 149).
} 
asociaría directamente con la autoridad derivada del dominio del ritual y las armas. En esa misma línea actuarían los espacios cultuales integrados a una cotidianidad ahora monumentalizada. En general, se había procedido a conectar los espacios de representación masculina y el lenguaje simbólico del poder (Balandier 1994). Estamos, pues, ante un escenario social patriarcal que articularía distintos modelos de representación en función del género: la excelencia masculina y la cotidianidad femenina, la monumentalización masculina y la invisibilización femenina.

\section{Referencias bibliográficas}

Alfayé, Silvia. 2009. "Espacios liminales y prácticas rituales en el Noroeste Peninsular". Acta Paleohispánica X. Paleohispánica 9: 107-111.

Amorós, Celia. 1994. Feminismo, igualdad y diferencia. México: Universidad Autónoma de México.

Aranda Jiménez, Gonzalo y José Antonio Esquivel. 2008. Poder y prestigio en las sociedades prehistóricas peninsulares: el contexto social del consumo de alimentos y bebidas. Granada: Departamento de Prehistoria y Arqueología de la Universidad de Granada.

Armada Pita, Xose Lois y Óscar García Revuelta. 2003. "Bronces con motivo de sacrificio del área Noroccidental de la Península Ibérica". AEspA 76: 47-75.

2008. “Carne, drogas o alcohol? Calderos y banquetes en el bronce final del Península Ibérica”. CPAG 18: 125-162.

Ayán, Xurxo M. y César Parcero. 2007. "Almacenamiento, unidades domésticas y comunidades en el Noroeste prerromano". Sistemas de almacenamiento entre los pueblos prerromanos de la Península. Coords. Rosario $\mathrm{G}^{\mathrm{a}}$ Huerta y David Rodríguez. Cuenca: Ediciones de la Universidad de Castilla-La Mancha. 367.

Balandier, George. 1994. El poder en escenas. De la representación del poder al poder de la representación. Barcelona: Paidós.

Blas Cortina, Miguel A. de. 2003. "Estelas con armas: arte rupestre y paleometalurgia en el norte de las Península Ibérica". Primer Symposium Internacional de Arte Prehistórico de Ribadesella. El arte prehistórico desde los inicios del siglo XXI. Coords. Primitiva Bueno Ramírez y Rodrigo de Balbín Behmann. Ribadesealla: Asociación Cultural Amigos de Ribadesealla. 391-417. 
2006. "La arquitectura como fin de un proceso: una revisión de la naturaleza de los túmulos prehistóricos sin cámaras convencionales de Asturias", Zephyrus 59: 233-255.

Bóveda González, Ma José. 1999. "As diademas castrexas de "Galicia”. Revista de Guimarães, Vol. Especial II: 539-560.

Bourdieu, Pierre. 1977. La reproducción. Elementos para una teoría del sistema de enseñanza. Barcelona: Laia.

. 1986. "The Forms of Capital". Handbook of Theory and Research for the Sociology of Education. Ed. John G. Richardson. New York, Greenwood. 241258.

Bradley, Richard y Ramón Fábregas. 1999. “La 'Ley de la Frontera': grupos rupestres galaico y esquemático y prehistoria del Noroeste de la Península Ibérica". Trabajos de Prehistoria 56, $\mathrm{n}^{\circ}$ 1: 103-114. 2005. Ritual and domestic life in Prehistoric Europe. London: Routledge.

Carballo Arceo, Xulio. 1986. Povoamento castrexo e romano da terra de Trasdeza. Santiago de Compostela: Xunta de Galiza.

Criado Boado, Felipe. 1993. "Visibilidad e interpretación del registro arqueológico". Trabajos de Prehistoria 50: 39-56.

Fábrega, Pastor. 2005. "Tiempo para el espacio. Poblamiento y territorio en la Edad del Hierro en la Comarca de Ortegal (A Coruña, Galicia)”. Complutum 16: 125-148.

Fábregas, Ramóny Richard Bradley. 1995a. "El silencio de las fuentes: prácticas funerarias en la Edad del Bronce del Noroeste y su contexto europeo". Complutum 6: 153-166.

1995b. "La realidad funeraria en el Noroeste del Neolítico a la Edad del Bronce". Arqueología da Morte. Xinzo de Limia. 95-125.

Fanjul, Alfonso. 2004. Los Castros de Asturias. Una revisión territorial y funcional. Teverga: Ayuntamiento de Teverga.

Fernández-Posse, Mª Dolores y Francisco J. Sánchez-Palencia. 1997. "Las comunidades campesinas en la cultura castreña". Trabajos de Prehistoria 55, $\mathrm{n}^{\circ}$ 2: 127-150.

. 1998. La investigación protohistórica en la Meseta y en Galicia. Madrid: Síntesis, Arqueología Prehistórica.

García y Fernández-Albalat, Blanca. 1990. Guerra y religión en la Gallaecia y Lusitania Antigu. La Coruña: Castro.

García Quintela, Marco V. 1999. Mitología y mitos de la Hispania prerromana III. Madrid: Akal. 
y Yolanda Seonae. 2011. "La larga vida de las rocas ourensanas", AEspA 84, 2011, 243-266.

García Vuelta, Óscar y Alicia Perea. 2001. "Las diademas-cinturón castreñas: el conjunto con decoración figurada de Moñes (Villamayor, Piloña, Asturias)". AEspA 74: 3-23.

González Ruibal, Alfredo. 2003. La experiencia del otro. Una introducción a la etnoarqueología. Madrid: Akal.

González Santana, Mónica. 2010. Las Mujeres del Noroeste Hispano en los Textos Grecolatinos. El mito de la Bárbara y las revisiones desde la arqueología y la epigrafía. Avilés: Nieva.

Hernando, Almudena. 2000. "Hombres del tiempo y mujeres del espacio: individualidad, poder e identidades de género". Arqueología Espacial 22: 23-44. .2002. Arqueología de la identidad. Madrid: Akal.

Iriarte, Ana. 2002. De amazonas a ciudadanos. Pretexto ginecocrático y patriarcado en la Grecia Antigua. Madrid: Akal.

Leach, Edmund. 1993. Cultura y comunicación. La lógica conexión de los símbolos. Madrid: Siglo XXI.

Loraux, Nicole. 2004. Las experiencias de Tiresias. Lo masculino y lo femenino en el mundo griego. Barcelona: El Acantilado.

Marco Simón, Francisco. 1994. "Heroización y tránsito acuático: Sobre las diademas de Mones (Piloña, Asturias)". Homenaje a J. M. Blázquez, II. Coords. Jaime Alvar y Julio Mangas J. Madrid: Ediciones Clásicas. 319-348.

Markale, Jean. 1992. Los celtas y la civilización celta. Madrid: Taurus.

Parcero Oubiña, César. 1993. "Aproximación al espacio social en el mundo castreño". Actas del XXII Congreso Nacional de Arqueología, vol. II, Vigo. 185-188. . 1995. "Elementos para el estudio de los paisajes castreños del Noroeste Peninsular". Trabajos de Prehistoria 52, n 1: 127-144.

2000. "Tres para dos. Las formas de poblamiento en la Edad del Hierro del Noroeste Ibérico". Trabajos de Prehistoria 57, n 1: 75-95.

Peñalver, Xabier. 2001. "El Bronce Final y la Edad del Hierro en la Euskal Herria atlántica: cromlechs y castros". Complutum 12: 51-71.

Peña Santos, Alberto y Jose Manuel Vázquez Varela. 1979. Los petroglifos gallegos. Cuadernos del Seminario de Estudios cerámicos de Sargadelos. La Coruña: Castro. 
Polignac, FranÇois. 1984. La naissance de la cité grecque. París: La Découverte.

Rodríguez Neila, Juan F. 1998. "Hispani príncipes. Algunas reflexiones sobre los grupos dirigentes de la Hispania prerromana". Cuadernos de Arqueología Universidad de Navarra 6: 99-137.

Sanchez- Palencia, Francisco J. 1983. Explotaciones auríferas en el Conventus Asturum. Indigenismo y Romanización en el Conventus Asturum, Madrid: Ministerio de Cultura y Universidad de Oviedo.

Santos Estévez, Manuel. 2008. "Petroglifos y paisaje social en la prehistoria reciente del noroeste de la Península Ibérica". TAPA 38. 1-216.

Sastre Prats, Inés. 2001. Las formaciones sociales rurales de la Asturia romana. Madrid: Ediciones clásicas.

. 2004. "La epigrafía de las Médulas. Escritura y sociedad". Cuadernos de la Fundación las Médulas, 4. 1-32.

Vázquez Varela, Jose Manuel. 1999. "Ideología y función de los grabados prehistóricos de Monte Bego (Francia)". Gallaecia 18: 73-88.

Villa Valdés, Ángel y Luis Cabo "Depósito funerario y recinto fortificado de la Edad del Bronce en el Castro del Chao Samartín: argumentos para su datación". Trabajos de Prehistoria 60, $\mathrm{n}^{\circ}$ 2: 143-151. 